\title{
DESEMPENHO DE CULTIVARES DE ALFACE DO GRUPO CRESPA EM JATAÍ-GO
}

\section{Júnio César de Souza Lima1, Letícia Martins de Sousa1, José Hortêncio Mota ${ }^{1}$, Geraldo Milanez de Resende ${ }^{2}$, Jony Eishi Yuri ${ }^{2}$}

\author{
${ }^{1}$ Universidade Federal de Goiás - Regional Jataí, Cx Postal 3, 75801-615, Jataí - GO, \\ junio_c@hotmail.com, leticia.martins.agro@gmail.com, hortenciomota@ufg.br \\ ${ }^{2}$ Embrapa Semiárido, Cx. Postal 23, 56302-970, Petrolina - PE, geraldo.milanez@embrapa.br, \\ jony.yuri@embrapa.br
}

Resumo - A alface é considerada a hortaliça folhosa mais consumida no Brasil, sendo que a escolha e determinação das cultivares a serem plantadas nas diferentes regiões, influência diretamente na produtividade da mesma. Objetivou-se com esse trabalho avaliar o comportamento de cinco cultivares de alface (Brida, Amanda, Cristal, Invicta e Verônica) do grupo solta crespa nas condições de Jataí-GO. O experimento foi instalado em delineamento de blocos casualizados com 4 repetições. As características avaliadas foram: altura e diâmetro de planta, número total de folhas, diâmetro e comprimento do caule, massa fresca total, comercial e do caule e percentual de massa seca. Verificou-se que apenas as características altura de plantas, comprimento do caule, diâmetro do caule, massa fresca do caule e massa fresca comercial apresentaram diferenças estatísticas em relação às cultivares avaliadas. As cultivares que apresentaram os maiores valores de massa fresca comercial foram Brida, Cristal e Verônica.

Palavras-chave: Lactuca sativa L., cultivares e produtividade.

Área do Conhecimento: Agronomia

\section{Introdução}

A alface (Lactuca sativa L.) é uma das hortaliças mais difundidas no mundo, possuindo grande importância econômica e também na alimentação humana constituindo-se a mais popular dentre aquelas em que as folhas são consumidas (COUTINHO et al., 2008).

O plantio da alface ao longo do ano é influenciado pela temperatura, fotoperíodo, umidade relativa e a disponibilidade hídrica, sendo que os fatores ambientais e genéticos, atuando conjuntamente por meio de processos fisiológicos, controlam o ótimo desenvolvimento da cultura (PUIATTI \& FINGER, 2005). Por tratar-se de uma hortaliça de inverno, seu desenvolvimento é bastante influenciado pelas condições ambientais. Temperaturas acima de $22^{\circ} \mathrm{C}$ estimulam o pendoamento, que é acelerado à medida que a temperatura aumenta e de acordo com Yuri et al. (2006), o cultivo da alface em outras estações do ano, favorece a incidência de doenças e a ocorrência de desequilíbrios nutricionais.

Diante disso, em regiões de clima tropical o cultivo de alface tem sido dificultado pelas altas temperaturas e a ampla luminosidade, afetando substancialmente o ciclo e a produção da cultura (CRUZ et al., 2012). A escolha de cultivares adaptadas a uma determinada região contribui para o sucesso da cultura e, consequentemente, elevando a renda do produtor (PUIATTI \& FINGER, 2005). Os resultados de cultivares não adaptadas às épocas de cultivo são plantas com menor desenvolvimento, com menor massa e número de folhas, não expressando, portanto, o seu máximo potencial genético, ocasionando assim um produto de baixa aceitação no mercado (SANTANA et al., 2005).

Ensaios de competição de cultivares efetuados sob as mais diversas situações têm demonstrado uma diversidade de comportamento, o desempenho de diferentes genótipos de alface tem sido observado nas diversas regiões do Brasil, onde cada cultivar expressa de forma distinta seu potencial genético quando submetidas em diferentes condições ambientais (SOUZA et al., 2008; SANTOS et al., 2009; SEABRA JÚNIOR et al., 2010; DAMASCENO et al., 2011; SCHUMACHER et al., 2012).

Neste contexto, o objetivo deste estudo foi avaliar o comportamento de cultivares de alface do grupo solta crespa, quanto ao rendimento produtivo, no verão, nas condições de Jataí, região Sudoeste do Estado de Goiás. 


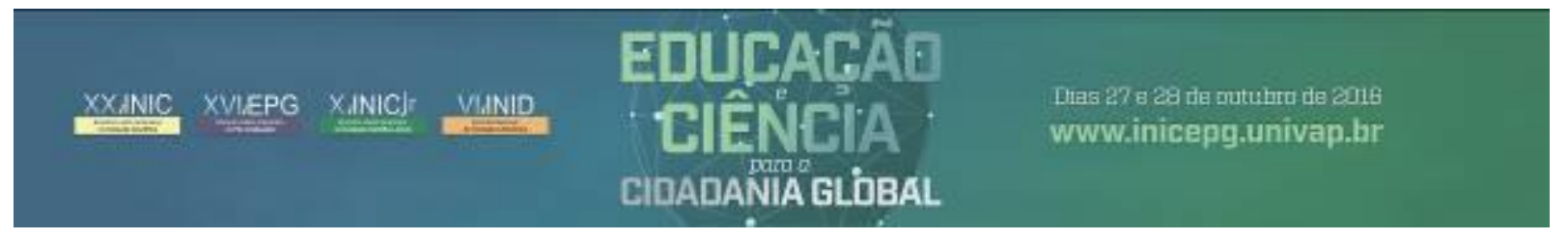

\section{Metodologia}

O experimento foi conduzido durante os meses de dezembro (18) de 2015 e janeiro (22) de 2016, na área de uma propriedade rural do município de Jataí, região Sudoeste de Goiás. O clima da região conforme a classificação de Köppen é Aw, tropical de savana, com temperatura média anual de $23,7^{\circ} \mathrm{C}$, precipitação anual média de $1644,9 \mathrm{~mm}$ e $670 \mathrm{~m}$ de altitude média (INMET, 2013). Os dados de precipitação e temperatura para o município de Jataí-GO durante a condução do experimento foram de $287,1 \mathrm{~mm}$ e temperaturas máxima e mínima de 34,9 e $19,6^{\circ} \mathrm{C}$, respectivamente (INMET, 2016).

O delineamento experimental utilizado foi de blocos casualizados, com 4 repetições, sendo os tratamentos constituídos por 5 cultivares de alface (Brida, Amanda, Cristal, Invicta e Verônica). O experimento foi conduzido em canteiros, sendo constituídos de parcelas com 1,5 m x 1,0 m, com espaçamento de $0,25 \mathrm{~m} \times 0,35 \mathrm{~m}$, dispostas em 4 linhas, totalizando 28 plantas por parcela.

As características do solo (Latossolo Vermelho Distroférrico de textura argilosa) utilizado foram: $\mathrm{pH}=5,7 \mathrm{em} \mathrm{CaCl} 2 ; \mathrm{P}=53,5 \mathrm{mg} \mathrm{dm}^{-3} ; \mathrm{K}=408 \mathrm{mg} \mathrm{dm}{ }^{-3} ; \mathrm{Ca}^{2+}=8,47 \mathrm{cmol}_{\mathrm{c}} \mathrm{dm}^{-3} ; \mathrm{Mg}^{2+}=2,53 \mathrm{cmol}_{\mathrm{c}}$ $\mathrm{dm}^{-3} ; \mathrm{Al}^{3+}=0,05 \mathrm{cmol}_{\mathrm{c}} \mathrm{dm}^{-3} ; \mathrm{H}+\mathrm{Al}=3,4 \mathrm{cmol}_{\mathrm{c}} \mathrm{dm}^{-3} ; \mathrm{Cu}=10 \mathrm{mg} \mathrm{dm}^{-3} ; \mathrm{Fe}=8 \mathrm{mg} \mathrm{dm}^{-3} ; \mathrm{Mn}=61,9 \mathrm{mg}$ $\mathrm{dm}^{-3} ; \mathrm{Zn}=14,5 \mathrm{mg} \mathrm{dm}^{-3} ; \mathrm{Na}=28,9 \mathrm{mg} \mathrm{dm}^{-3}$ e $\mathrm{MO}=27 \mathrm{~g} \mathrm{dm}^{-3}$.

Durante a instalação do experimento o solo foi arado, gradeado, e em seguida os canteiros confeccionados com o auxílio de um rotoencanteirador, sendo aplicados $200 \mathrm{~g}$ por parcela do adubo comercial 4-30-16, $150 \mathrm{~g}$ de termofosfato magnesiano (composto por $\mathrm{P}_{2} \mathrm{O}_{5}$ total $=16 \%$; $\mathrm{P}_{2} \mathrm{O}_{5}$ Sol. Ácido Cítrico = 12\%; $\mathrm{Ca}=16 \% ; \mathrm{Mg}=6,5 \% ; \mathrm{S}=6 \% ; \mathrm{B}=0,1 \% ; \mathrm{Cu}=0,05 \% ; \mathrm{Mn}=0,3 \% ; \mathrm{Si}=9 \% ; \mathrm{Zn}$ $=0,55 \%)$ por parcela e $200 \mathrm{~g}$ de calcário magnesiano por parcela.

As mudas foram produzidas em bandejas de isopor de 288 células, contendo substrato comercial Carolina ${ }^{\circledR}$ e conduzidas em ambiente protegido até o transplantio aos 34 dias após semeadura (DAS). As plantas foram mantidas em sistema de irrigação por aspersão convencional até a colheita aos 69 DAS.

Foram avaliadas na ocasião da colheita: altura das plantas (efetuada desde o nível do solo até o topo da planta com o auxílio de uma régua graduada), diâmetro das plantas (foi realizada nas margens da planta feita com o auxílio de uma régua graduada), número de folhas (obtido por meio da contagem de todas as folhas da planta), diâmetro de caule (por meio de um paquímetro digital); comprimento do caule (por meio de uma régua graduada), massa fresca total (plantas cortadas rente ao solo e pesadas) e comercial (pesadas somente às cabeças comerciais, retirando-se as folhas externas danificadas), massa fresca de caule (obtida por meio da pesagem da porção de caule presente na cabeça, sem as folhas, realizada imediatamente após a colheita) e percentual de massa seca (amostras de folhas foram secas em estufa com circulação forçada de ar a $65-70^{\circ} \mathrm{C}$, até peso constante).

Os dados coletados foram submetidos à análise de variância e as médias dos tratamentos foram comparadas pelo teste Scott-Knott adotando-se o nível de $5 \%$ de significância utilizando-se o programa computacional Sisvar 5.1 (FERREIRA, 2011).

\section{Resultados}

$\mathrm{Na}$ Tabela 1 são apresentados os resultados da análise de variância $(p<0,05)$ para todas as variaveis analisadas.

Tabela 1. Análise de variância para as características altura média $(H)$, largura de planta (LP), número de folhas (NF), comprimento do caule (CC), diâmetro do (DC), massa fresca total (MFT), massa fresca comercial (MFCo), massa fresca de caule (MFC), percentual de massa seca (\%MS) das cinco cultivares de alface crespa cultivadas em Jataí - GO.

\begin{tabular}{|c|c|c|c|c|c|c|c|c|c|c|}
\hline \multirow{2}{*}{\multicolumn{2}{|c|}{ Causas de Variação GL }} & \multicolumn{9}{|c|}{ Quadrados Médios } \\
\hline & & $\mathbf{H}$ & LP & NF & CC & DC & MFT & MFCo & MFC & $\% M S$ \\
\hline Blocos & 3 & 3,959 & 10,301 & 4,719 & 2,758 & 4,467 & 0,005 & 0,003 & 88,213 & 1,829 \\
\hline Cultivares & 4 & 27,632 & $6,885^{\text {ns }}$ & $30,324^{n}$ & $37,549^{*}$ & $21,571^{*}$ & $0,005 n$ & $0,008^{*}$ & $279,420^{*}$ & $0,857^{\text {ns }}$ \\
\hline Erro & 12 & 2,543 & 5,169 & 4,021 & 1,632 & 2,911 & 0,002 & 0,002 & 14,060 & 0,509 \\
\hline CV (\%) & & & 6,7 & 16,2 & 15,3 & 9,2 & 16,2 & 7,2 & 14,3 & 12,7 \\
\hline
\end{tabular}

XX Encontro Latino Americano de Iniciação Científica, XVI Encontro Latino Americano de Pós-Graduação e VI 2 Encontro de Iniciação à Docência - Universidade do Vale do Paraíba. 


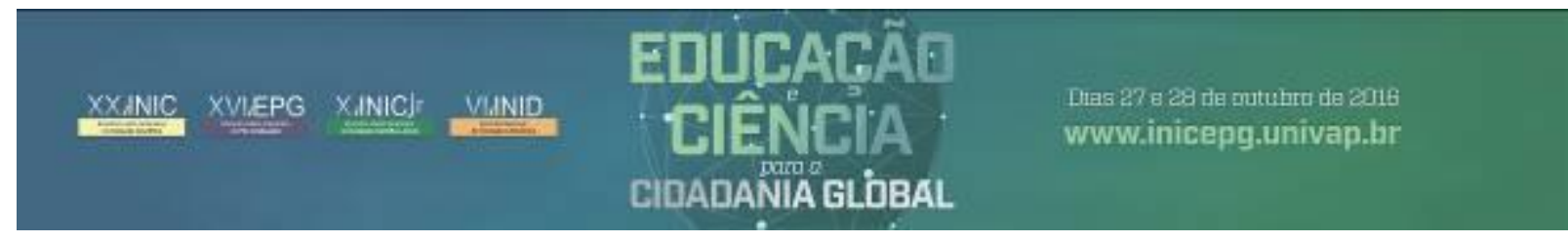

Em que: $n s=$ não significativo $e^{*}=$ significativo pelo Teste $F(p<0,05)$.

Tabela 2. Resumo do teste de médias para as características altura média $(H)$, largura de planta (DP), número de folhas (NF), comprimento do caule (CC), diâmetro do caule (DC), massa fresca total (MFT), massa fresca comercial (MFCo), massa fresca de caule (MFC), percentual de massa seca (\%MS) das cinco cultivares de alface crespa cultivadas em Jataí - GO.

\begin{tabular}{cccccccccc}
\hline Cultivares & H & LP & NF & CC & DC & MFT & MFCo & MFC & $\%$ MS \\
\hline Amanda & $20,15 \mathrm{c}$ & $31,35 \mathrm{a}$ & $18 \mathrm{a}$ & $6,58 \mathrm{~b}$ & $24,15 \mathrm{~b}$ & $290,0 \mathrm{a}$ & $230,0 \mathrm{~b}$ & $20,80 \mathrm{~b}$ & $7,26 \mathrm{a}$ \\
Invicta & $22,95 \mathrm{~b}$ & $33,00 \mathrm{a}$ & $20 \mathrm{a}$ & $7,10 \mathrm{~b}$ & $25,43 \mathrm{~b}$ & $315,0 \mathrm{a}$ & $245,5 \mathrm{~b}$ & $24,20 \mathrm{~b}$ & $7,29 \mathrm{a}$ \\
Brida & $23,15 \mathrm{~b}$ & $29,55 \mathrm{a}$ & $25 \mathrm{a}$ & $6,55 \mathrm{~b}$ & $28,58 \mathrm{a}$ & $347,5 \mathrm{a}$ & $302,5 \mathrm{a}$ & $30,70 \mathrm{a}$ & $7,08 \mathrm{a}$ \\
Cristal & $24,95 \mathrm{a}$ & $32,10 \mathrm{a}$ & $23 \mathrm{a}$ & $5,93 \mathrm{~b}$ & $29,84 \mathrm{a}$ & $357,5 \mathrm{a}$ & $335,0 \mathrm{a}$ & $29,60 \mathrm{~b}$ & $6,29 \mathrm{a}$ \\
Verônica & $27,25 \mathrm{a}$ & $32,25 \mathrm{a}$ & $23 \mathrm{a}$ & $13,32 \mathrm{a}$ & $26,29 \mathrm{~b}$ & $382,5 \mathrm{a}$ & $292,5 \mathrm{a}$ & $42,70 \mathrm{a}$ & $7,48 \mathrm{a}$ \\
\hline
\end{tabular}

Em que: médias seguidas por letras iguais na coluna não diferem entre si pelo teste de Scott Knott a $5 \%$ de probabilidade.

\section{Discussão}

Observa-se que não houve diferença estatística para as características diâmetro de planta, número de folha, massa fresca total e percentual de massa seca (Tabela 1). Diferindo estatisticamente para as variáveis, altura de planta, comprimento do caule, diâmetro do caule, massa fresca comercial e massa fresca do caule.

Para a variável altura de planta, que compreende a distância entre a base da planta até seu ápice, as cultivares Verônica e Cristal foram estatisticamente superiores às demais cultivares, apresentando altura média de $27,25 \mathrm{~cm}_{\text {planta }}^{-1}$ e $24,95 \mathrm{~cm}$ planta ${ }^{-1}$, respectivamente. Sendo que a cultivar Amanda apresentou menor altura com média de $20,15 \mathrm{~cm}_{\text {planta }}{ }^{-1}$.

Quanto ao diâmetro de planta e número de folhas não foram constatadas diferenças estatísticas entre as cultivares, sendo que as plantas apresentaram diâmetro médio de $31,65 \mathrm{~cm}$ e em média 22 folhas planta-1 (Tabela 2).

Segundo Sala \& Costa (2012), as características das plantas de alface como o diâmetro e a altura, são importantes pois fornecem informações, para o acondicionamento das plantas para o transporte em caixas plásticas ou de madeira. Na produção de alface, o número de folhas é uma característica importante e está intimamente associado à temperatura do ambiente de cultivo e ao fotoperíodo (OLIVEIRA et al., 2004).

Blat et al. (2011) verificaram que apesar das cultivares de alface crespa terem diferido em massa de folhas, o número total de folhas foi estatisticamente semelhante para todas elas, corroborando com este estudo. De acordo com Sediyama et al. (2000), o tamanho exagerado de folhas muitas vezes é indesejável pela dificuldade de embalagem pelos danos causados às folhas.

Para variável comprimento do caule, que é um dos fatores indicativos a tolerância ao pendoamento a cultivar Verônica diferiu estatisticamente entre as demais, sendo esta superior com um comprimento do caule de $13,32 \mathrm{~cm}$ planta $^{-1}$ (Tabela 2). Apesar da cultivar Verônica não apresentar visualmente características de pendoamento, seu índice médio de caule foi superior ao proposto por Yuri et al. (2006) e Resende et al. (2004), que propõem que o tamanho de caule mais adequado para a comercialização deve-se encontrar na faixa de 6,0 a 9,0 cm de comprimento, acima desses valores não são recomendadas. Portanto, com exceção da cultivar Verônica, as cultivares avaliadas estão aptas para a comercialização, podendo constatar que elas não apresentaram indícios de pendoamento.

Estas diferenças observadas geralmente são atribuídas à característica genética de cada cultivar, mas também podem ser influenciadas pelo ambiente de cultivo, uma vez que estes fatores podem ser responsáveis pelas mudanças fisiológicas e morfológicas das plantas (SUINAGA et al., 2013).

Para o diâmetro do caule, as cultivares Brida e Cristal foram superiores estatisticamente, com 28,58 e 29,84 cm, respectivamente (Tabela 2). Suinaga et al. (2013), avaliando o desempenho de cultivares de alface crespa, observaram que a cultivar Solaris apresentou maior diâmetro do caule.

Em relação à massa fresca total, esta não apresentou diferença estatística entre as cultivares, tendo uma média de 338,50 $\mathrm{g}_{\text {planta- }}{ }^{-1}$ (Tabela 2). Houve diferença estatística entre as cultivares, para a característica massa fresca comercial de plantas, sendo que as cultivares Cristal, Brida e Verônica

XX Encontro Latino Americano de Iniciação Científica, XVI Encontro Latino Americano de Pós-Graduação e VI 3 Encontro de Iniciação à Docência - Universidade do Vale do Paraíba. 


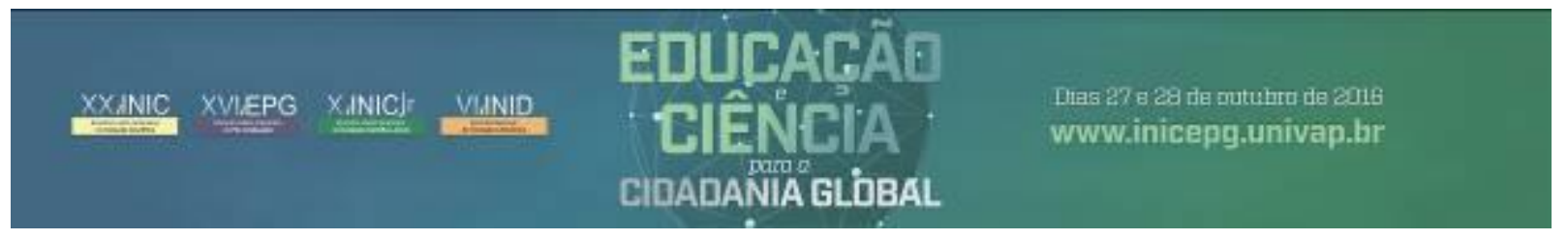

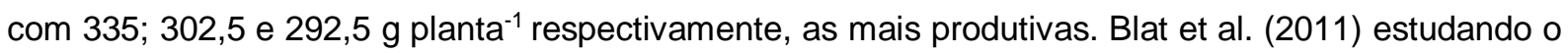
desempenho de cultivares de alface crespa encontraram massa fresca e seca para a cultivar Verônica de 118,7 e 6,4 g planta $^{-1}$, respectivamente. Suinaga et al. (2013) obtiveram para a cultivar Verônica a massa fresca comercial de $682,5 \mathrm{~g}$ planta $^{-1}$. Estes resultados diferem dos resultados encontrados neste experimento, sendo que esta diferença pode estar atribuída às condições climáticas do local de implantação do experimento, pois em Jataí - GO a implantação ocorreu no verão, durante a época mais estressante para o cultivo de alface.

Para a massa fresca do caule, observa-se que as cultivares Verônica Brida se destacaram em relação às demais, com 42,70 e 30,70 $\mathrm{g}_{\text {planta }}{ }^{-1}$, respectivamente (Tabela 2). Observa-se que no mercado in natura, deseja-se uma menor massa fresca do caule, pois no preparo de saladas, descarta-se o caule e aproveita somente as folhas.

Sanchez (2007) observou em seu estudo, que a cultivar Verônica apresentou maior massa fresca de caule, corroborando com este trabalho. Esses resultados concordam com os obtidos por Sediyama et al. (2000), Oliveira et al. (2003) e Churata Masca \& Gomes (2004). No caso do caule, esse maior valor torna-se um aspecto negativo, sugerindo que a cultivar possa ter maior susceptibilidade ao pendoamento (SANCHEZ, 2007).

Para o percentual de massa seca, não houve diferença estatística entre as cultivares, apresentando uma média de 7,08\% (Tabela 2). Para Blat et al. (2011), as melhores cultivares levando-se em consideração os resultados de massa seca, são a Crespona Gigante e Verônica, tendo estas, um melhor desempenho.

\section{Conclusão}

Apenas as características altura de plantas, comprimento do caule, diâmetro do caule, massa fresca do caule e massa fresca comercial apresentaram diferenças estatísticas em relação às cultivares avaliadas.

As cultivares que apresentaram os maiores valores de massa fresca comercial foram Brida, Cristal e Verônica.

\section{Referências}

BLAT, S.F; SANCHEZ, S.V.; ARAÚJO, J.A.C.; BOLONHEZI, D. Desempenho de cultivares de alface crespa em dois ambientes de cultivo em sistema hidropônico. Horticultura Brasileira, v. 29, n. 1, p. 135-138, 2011.

CHURATA MASCA, M.G.C.; GOMES, J.A. Acúmulo de matéria seca em genótipos de alface sob cultivo hidropônico-NFT, nas condições de Jataí-GO. Horticultura Brasileira, v. 22, n. 2, 2004. (Suplemento CD-ROM)

COUTINHO, E.L.M.; CARVALHO, F.P. ; FRANCO, H.C.J.; ORIOLI JÚNIOR, V. COUTINHO NETO, A. M.; UETA, F. Z. Adubação fosfatada em cultivares de alface cultivada em solos deficientes. Nucleus, v.5, n.2, p. $279-287.2008$.

CRUZ, T.P.; JUNGER, L.A.; RABELLO, L.K.C.; SILVA, L.G.; PASSOS, R.R. Desempenho agronômico de cultivares de alface para as condições edafoclimáticas da região de Alegre - ES Nucleus, v.9, n.2, p. $43-50.2012$

DAMASCENO, L.A; GUIMARÃES M. A; BOHORQUEZ A.C.C; GUIMARÃES A.R. Desempenho de cultivares de alface na mesorregião do Alto Solimões, Amazonas. Horticultura Brasileira. v.29 n. 1. p.135-138. 2011

FERREIRA, D.F. Sisvar: A computer statistical analysis system. Ciência e Agrotecnologia, v.35, n.6, p.1039-1042, 2011.

INMET - INSTITUTO NACIONAL DE METEOROLOGIA. BDMEP - Banco de Dados Meteorológicos para Ensino e Pesquisa: Série Histórica - Dados Diários de 01/01/1982 a 31/12/2012 Estação: 83464

XX Encontro Latino Americano de Iniciação Científica, XVI Encontro Latino Americano de Pós-Graduação e VI 4 Encontro de Iniciação à Docência - Universidade do Vale do Paraíba. 


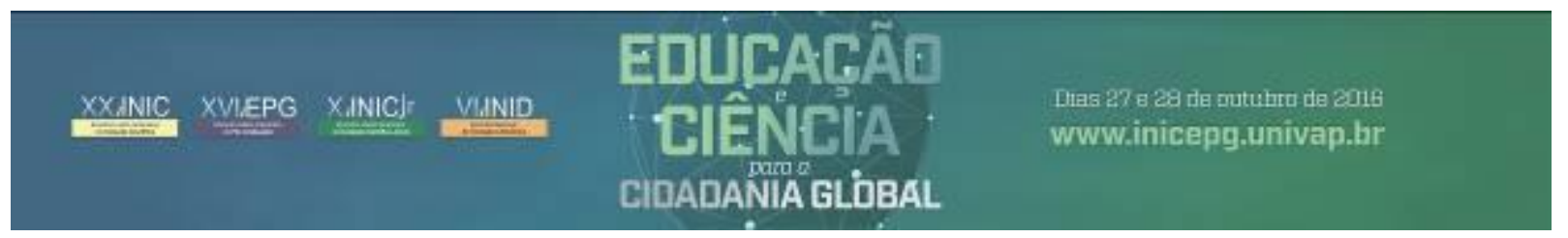

- JATAI - GO. 2013. Disponível em: shttp://www.inmet.gov.br/portal/index.php?r=bdmep/bdmep>. Acesso 6 jun. 2015.

INMET - INSTITUTO NACIONAL DE METEOROLOGIA. BDMEP - Banco de Dados Meteorológicos para Ensino e Pesquisa: Série Histórica - Dados Diários de 18/12/2015 a 22/01/2016 Estação: 83464 - Jatai - GO. 2016. Disponível em: shttp://www.inmet.gov.br/portal/index.php?r=bdmep/bdmep >. Acesso em: 04 jul. 2016.

OLIVEIRA, A.C.B.; SEDIYAMA, M.A.N.; PEDROSA, M.W.; GARCIA, N.C.; GARCIA, S.L.R. Divergência genética e descarte de variáveis em alface cultivada sob sistema hidropônico. Acta Scientiarum Agronomy, v. 26, p. 211-217, 2004.

OLIVEIRA, C.E.P.; LUZ, J.M.Q.; MARTINS, S.T.; DINIZ, K. A.; CARLIS, G.C.; SILVA, A.M. Produção de cultivares de alface em sistema hidropônico com perfis parciais ou totalmente pintados de branco. In: CONGRESSO BRASILEIRO DE OLERICULTURA, 43. Resumos... Recife: ABH, 2003. (CD$\mathrm{ROM})$.

PUIATTI, M.; FINGER, F.L. Fatores climáticos. In: FONTES, P.C. Olericultura: teoria e prática. Viçosa: UFV. 2005. p. 17-30.

RESENDE, G.M. Características produtivas, qualidade pós-colheita e teor de nutrientes em alface americana (Lactuca sativa L.) sob doses de nitrogênio e molibdênio, em cultivo de verão e de inverno. 2004. 139 f. Tese (Doutorado em Agronomia) - Universidade Federal de Lavras, Lavras-MG.

SALA, F.C.; COSTA, C.P. Retrospectiva e tendência da alfacicultura brasileira. Horticultura Brasileira, v. 30, n. 1, p. 187-194, 2012.

SANCHEZ, S.V. Avaliação de cultivares de alface crespa produzidas em hidroponia tipo NFT em dois ambientes protegidos em Ribeirão Preto (SP). 2007. 63 f. Dissertação (Mestrado em Agronomia) Faculdade de Ciências Agrárias e Veterinárias - UNESP, Jaboticabal, SP.

SANTANA, C. V. S.; ALMEIDA, A.C.; FRANÇA, F. S.; TURCO, S. H. N.; DANTAS, B. F.; ARAGÃO, C. A. Influência do sombreamento na produção de alface nas condições climáticas do semi-árido nordestino. In: CONGRESSO BRASILEIRO DE OLERICULTURA, 45. 2005. Resumos... Fortaleza: SOB, (CDROM).

SANTOS, C.L; SEABRA J.R.S; GADUM DE LALLA, J.; THEODORO, V.C.A; NESPOLI, A. Desempenho de cultivares de alface tipo crespa sob altas temperaturas. Horticultura Brasileira v. 27 n.2. S3157-S3162. 2009.

SCHUMACHER, P.V; MOTA, J.H; YURI J.E; RESENDE, G.M: Competição de cultivares de alface em Jataí-GO. Horticultura Brasileira v. 30 n. 2. S2727-S2731. 2012

SEABRA JÚNIOR, S.; SOUZA, S.B.S; NEVES, L.G.; THEODORO, V.C.A; NUNES, M.C.M; NASCIMENTO, A.S; RAMPAZZO, R.; LUZ, A.O; LEÃO, L.L. Desempenho de cultivares de alface tipo crespa sob diferentes telas de sombreamento no período de inverno. Horticultura Brasileira v.28 n. 2. S252-S259. 2010.

SEDIYAMA, M.A.N.; PEDROSA, M.W.; GARCIA, N.C.P.; GARCIA, S.R.L. Seleção de cultivares de alface para cultivo hidropônico. Horticultura Brasileira, v. 18, p. 244-245, 2000.

SOUZA, M.C.M; RESENDE L.V; MENEZES, D; SANTOS, V.F. Avaliação de progênies de alface quanto ao pendoamento e florescimento precoce. In: CONGRESSO BRASILEIRO DE OLERICULTURA, 48; 2008. Resumos... Maringá: ABH (CD-ROM).

XX Encontro Latino Americano de Iniciação Científica, XVI Encontro Latino Americano de Pós-Graduação e VI 5 Encontro de Iniciação à Docência - Universidade do Vale do Paraíba. 


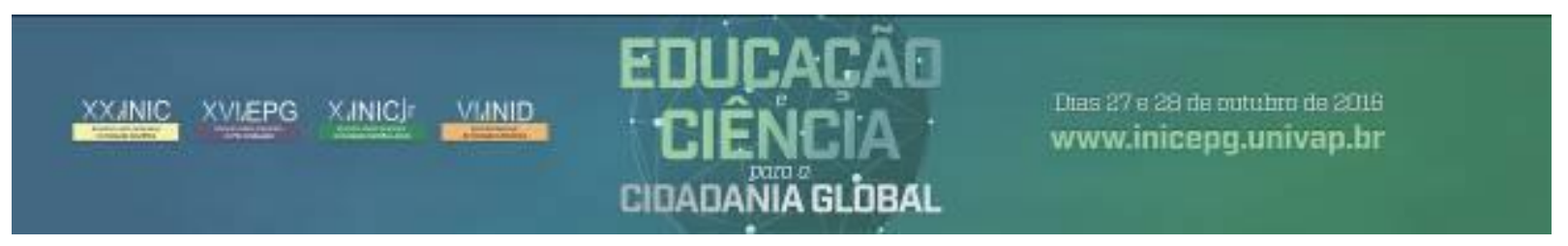

SUINAGA, F.A.; BOITEUX, L.S.; CABRAL, C.S.; RODRIGUES, C.S. Desempenho produtivo de cultivares de alface crespa, Brasília: Embrapa, 2013. 15p. (Boletim de Pesquisa e Desenvolvimento, 89)

YURI, J.E.; RESENDE, G.M.; MOTA, J.H.; SOUZA, R.J. Competição de cultivares de alfaceamericana no sul de Minas Gerais. Caatinga, v. 19, n. 1, p. 98-102, 2006. 